\title{
Differential metabolic responses in three life stages of mussels Mytilus galloprovincialis exposed to cadmium
}

\author{
Huifeng $\mathrm{Wu}^{1} \cdot$ Lanlan $\mathrm{Xu}^{1,2} \cdot$ Deliang $\mathrm{Yu}^{1,2} \cdot$ Chenglong $\mathrm{Ji}^{1}$
}

Accepted: 19 October 2016 / Published online: 28 October 2016

(C) Springer Science+Business Media New York 2016

\begin{abstract}
Cadmium (Cd) is one of the most important metal contaminants in the Bohai Sea. In this work, NMR-based metabolomics was used to investigate the toxicological effects of $\mathrm{Cd}$ at an environmentally relevant concentration $\left(50 \mu \mathrm{g} \mathrm{L}^{-1}\right)$ in three different life stages (D-shape larval, juvenile and adult) of mussels Mytilus galloprovincialis. Results indicated that the D-shape larval mussel was the most sensitive life stage to $\mathrm{Cd}$. The significantly different metabolic profiles meant that $\mathrm{Cd}$ induced differential toxicological effects in three life stages of mussels. Basically, Cd caused osmotic stress in all the three life stages via different metabolic pathways. Cd exposure reduced the anaerobiosis in D-shape larval mussels and disturbed lipid metabolism in juvenile mussels, respectively. Compared with the D-shape larval and juvenile mussels, the adult mussels reduced energy consumption to deal with Cd stress.
\end{abstract}

Keywords Mytilus galloprovincialis · Cadmium • Toxicological effects $\cdot$ NMR $\cdot$ Metabolomics

Huifeng Wu

hfwu@yic.ac.cn

1 Key Laboratory of Coastal Zone Environmental Processes, Yantai Institute of Coastal Zone Research (YIC), Chinese Academy of Sciences (CAS), Shandong Provincial Key Laboratory of Coastal Zone Environmental Processes, YICCAS, Yantai 264003, P. R. China

2 University of Chinese Academy of Sciences, Beijing 100049, P. R. China

\section{Introduction}

The increasing metal pollution has posed great risk on coastal environment and animals (Broeg et al. 2005). As a non-essential metal, cadmium $(\mathrm{Cd})$ has become a typical marine and coastal metal contaminant. Although $\mathrm{Cd}$ is relatively rare in marine environment, with concentrations in seawater ranging from $2 \times 10^{-4}$ to $2.9 \mu \mathrm{g} \mathrm{L}^{-1}$, the concentration of $\mathrm{Cd}$ has reached $50 \mu \mathrm{g} \mathrm{L}^{-1}$ in some heavily polluted estuaries or harbors and ports (Chester 1990). Sun et al. (2011) reported that $\mathrm{Cd}$ was one of the important metal contaminants in the sediments from the Bohai coast. $\mathrm{Cd}$ can inactivate many metabolic enzymes by competing for the catalytic sites with other metals (Bouilly et al. 2006; Chang et al. 2009). Furthermore, $\mathrm{Cd}$ can induce oxidative stress in animals by producing excessive reactive oxygen species (Company et al. 2004). Since Cd has become one of the most severe metal contaminants, it is necessary to characterize the toxicological effects of $\mathrm{Cd}$ in marine animals.

As an-omic technique, metabolomics is the systematic study of metabolite fingerprints that may be affected by the external stimuli in organisms (Brindle et al. 2002; Bundy et al. 2004; Lindon et al. 2000). The well-established NMR spectroscopy-based metabolomics can provide valuable biological information induced by both endogenous and exogenous factors, through the analysis of biofluids and tissues (Lindon et al. 2000). Due to the rapid quantitative measurement, ${ }^{1} \mathrm{H}$ NMR spectroscopy is suited to detect a large range of endogenous low-molecular weight metabolites $(<1000 \mathrm{Da})$ in biological samples with a high throughput, which allows a global analysis on the metabolomes to characterize the metabolic responses induced by external stimuli, such as environmental contaminants.

Since marine mussels are ubiquitous, sedentary filterfeeders and can accumulate high amounts of contaminants 
from marine and coastal environments, they are frequently used as bioindicators for marine and coastal environmental contaminants (O'Connor 1998). The species of blue mussel Mytilus galloprovincialis is widely distributed along the Bohai coast and popularly consumed as seafood by local residents. In this work, we planned to use mussel M. galloprovincialis as the experimental animal to study the toxicological effects of Cd. However, evidences have indicated that the earlier life stages are more sensitive than the adults to environmental contaminants (Giacomin et al. 2013). To compare the differential metabolic responses in different life stages of mussels M. galloprovincialis, the D-shape larval, juvenile and adult mussels were exposed to $\mathrm{Cd}$ at an environmentally relevant concentration $\left(50 \mu \mathrm{g} \mathrm{L}^{-1}\right)$ for $48 \mathrm{~h}$. NMR-based metabolomics was conducted on these mussel samples to elucidate the differential toxicological effects of $\mathrm{Cd}$ in these three life stages of mussels M. galloprovincialis.

\section{Materials and methods}

\section{Larvae breeding and experimental design}

Sexually matured mussels for larvae breeding were collected in April 2015 from a pristine site in the farming area near to the Yangma Island (Yantai, China). All mussels were transported to the laboratory and acclimatized in aerated natural seawater (salinity $31 \mathrm{psu}$ ) at $21^{\circ} \mathrm{C}$ for 7 days. After acclimatization, these mussels were kept in the air in dark place for $2 \mathrm{~h}$. Then each mussel was put into a beaker containing warmer seawater $\left(24^{\circ} \mathrm{C}\right)$. After $2 \mathrm{~h}$, the majority of mussels came to ovulation and spermiation. The 500 mesh sieve screen was used to filter impurities. Then the sperms and eggs were quickly collected, respectively, to fertilize. All the fertilized eggs were then transferred into 50 $\mathrm{L}$ of normal filtered seawater (FSW) in a bucket. Continuous aeration was conducted during incubation. After approximately $48 \mathrm{~h}$, the majority of fertilized eggs developed into D-shape larvae (Fig. 1a). Then the D-shape larval mussels were divided into two groups (control and $\mathrm{Cd}$ exposure) each containing 8 buckets (30 L) with a density of $\sim 25$ D-shape larvae per milliliter. The environmentally relevant concentration $\left(50 \mu \mathrm{g} \mathrm{L}^{-1}\right)$ of $\mathrm{Cd}$ was selected for the exposures of $\mathrm{D}$-shape larval mussels $M$. galloprovincialis. During the acclimatization and exposure periods, all the larvae were kept under a photoperiod of $12 \mathrm{~h}$ light and $12 \mathrm{~h}$ dark, and fed with the Chlorella vulgaris daily. After exposure for $48 \mathrm{~h}$, all the larvae $\left(\sim 6.0-7.5 \times 10^{5}\right.$ individuals) from each bucket were immediately filtered out by 500 mesh sieve screen and collected into two larvae samples. These D-shape larval mussel samples were quickly snap-frozen in liquid nitrogen and stored at $-80^{\circ} \mathrm{C}$.

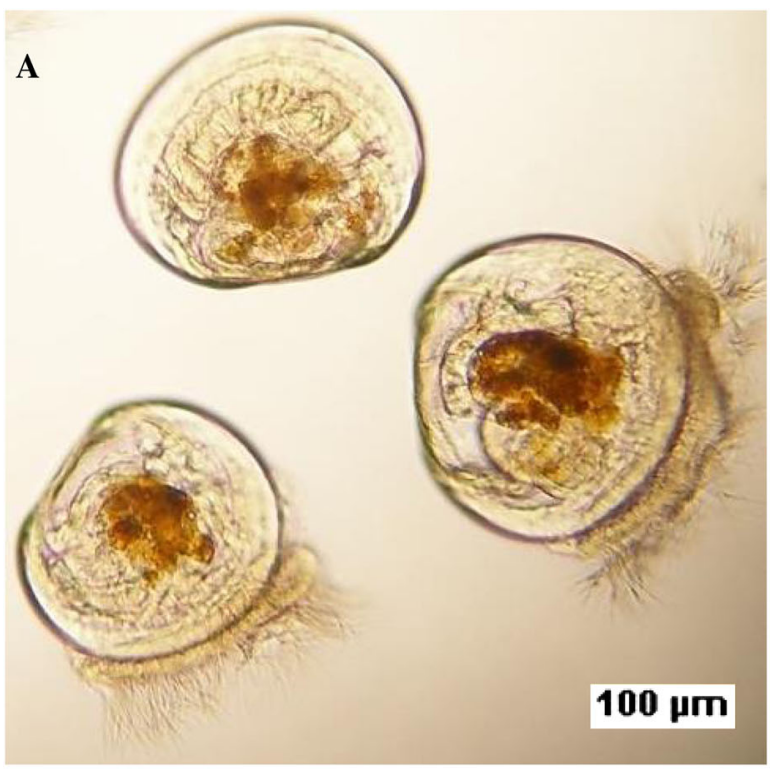

B
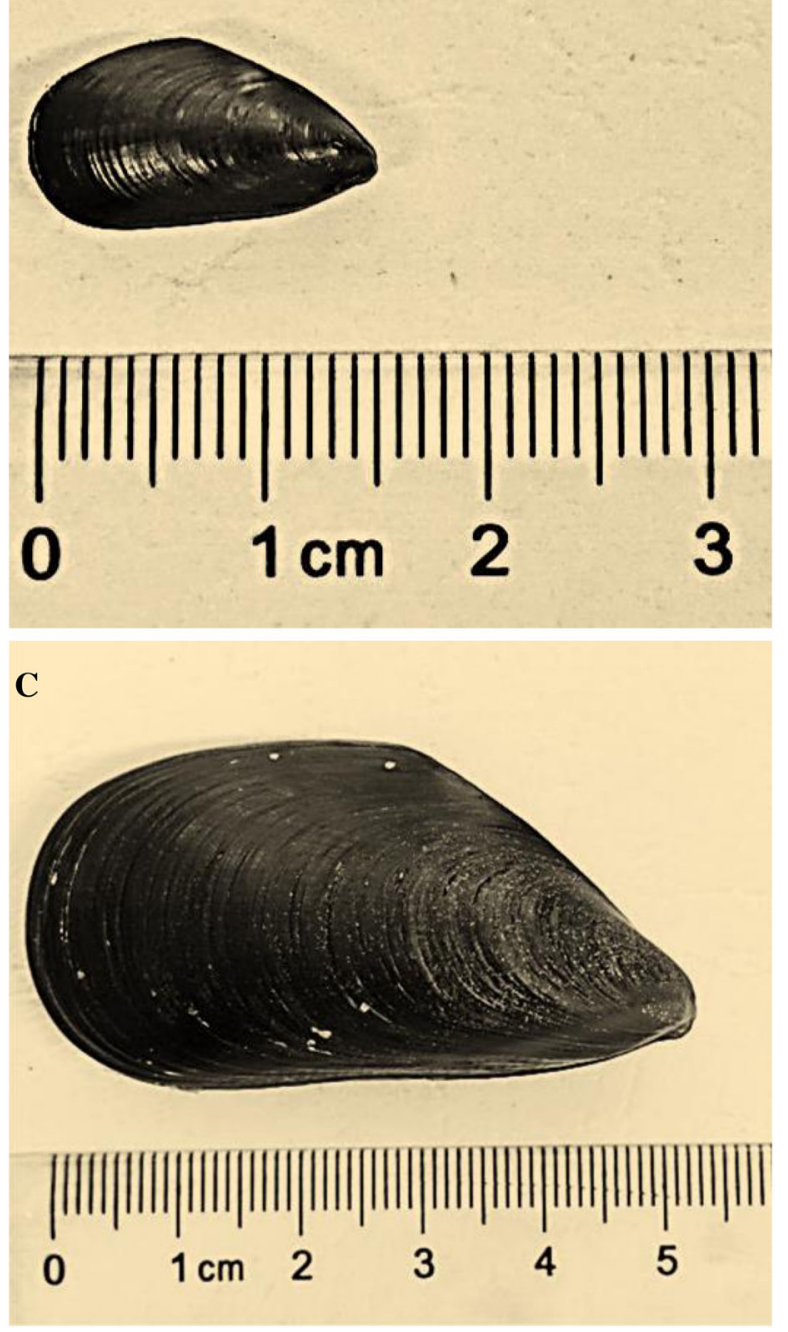

Fig. 1 The mussels $M$. galloprovincialis of three life stages used in this study, a D-shape larvae, $\mathbf{b}$ juvenile and $\mathbf{c}$ adult 
Thirty juvenile (length: $1.0-1.5 \mathrm{~cm}$, Fig. 1b) and thirty adult (length: $4.5-5.5 \mathrm{~cm}$, Fig. 1c) mussels for treatments were collected from the same sampling site to the mussels for larvae breeding. For both juvenile and adult mussels, the experimental procedures were identical. After transported to laboratory, the mussels were allowed to acclimate in aerated seawater $\left(21^{\circ} \mathrm{C}, 31 \mathrm{psu}\right)$ in the laboratory for $7 \mathrm{~d}$ and fed with the Chlorella vulgaris Beij at a ratio of $2 \%$ tissue dry weight daily. After acclimatization, the mussels were randomly divided into two groups (control and $\mathrm{Cd}$ exposure) containing fifteen individuals in $20 \mathrm{~L}$ of aerated seawater. The same concentration $\left(50 \mu \mathrm{g} \mathrm{L}{ }^{-1}\right)$ of $\mathrm{Cd}$ was used for the exposure. After exposure for $48 \mathrm{~h}$, the whole soft tissues from both juvenile and adult mussels were dissected quickly. The samples of whole soft tissues were flash-frozen in liquid nitrogen and stored at $-80{ }^{\circ} \mathrm{C}$ before further procedures. During the exposure periods, all the experimental conditions for both juvenile and adult mussels were completely identical to those for D-shape larval mussels.

\section{Metabolite extraction}

Each mussel samples was ground into powder in liquid nitrogen. Polar metabolites in these mussel samples were extracted by the modified extraction protocol as described previously (Ji et al. 2013). Briefly, each mussel sample (ca. $100 \mathrm{mg}$ wet weight) was homogenized and extracted in $4 \mathrm{~mL} \mathrm{~g}^{-1}$ of methanol, $5.25 \mathrm{~mL} \mathrm{~g}^{-1}$ of water and $2 \mathrm{~mL} \mathrm{~g}^{-1}$ of chloroform. The methanol/water layer with polar metabolites was transferred to a glass vial and dried in a centrifugal concentrator. The extracts were then re-suspended in $600 \mu \mathrm{L}$ of phosphate buffer $\left(100 \mathrm{mM} \mathrm{Na}_{2} \mathrm{HPO}_{4}\right.$ and $\mathrm{NaH}_{2} \mathrm{PO}_{4}$, including $0.5 \mathrm{mM}$ TSP, $\mathrm{pH} 7.0$ ) in deuterium oxide $\left(\mathrm{D}_{2} \mathrm{O}\right)$. The mixture was vortexed and then centrifuged at $3000 \mathrm{~g}$ for $5 \mathrm{~min}$ at $4{ }^{\circ} \mathrm{C}$. The supernatant substance $(550 \mu \mathrm{L})$ was then pipetted into a $5 \mathrm{~mm}$ NMR tube prior to NMR analysis.

\section{${ }^{1}$ H NMR spectroscopy}

Metabolite extracts of mussel samples were analyzed on a Bruker AV 500 NMR spectrometer performed at 500.18 $\mathrm{MHz}$ (at $25^{\circ} \mathrm{C}$ ) as described previously (Ji et al. 2013). All ${ }^{1} \mathrm{H}$ NMR spectra were phased, baseline-corrected, and calibrated (TSP at $0.0 \mathrm{ppm}$ ) manually using TopSpin (version 2.1, Bruker).

\section{Spectral pre-processing and multivariate analysis}

All one dimensional ${ }^{1} \mathrm{H}$ NMR spectra were converted to a data matrix using the custom-written ProMetab software in Matlab version 7.0 (The MathsWorks, Natick, MA) (Ji et al. 2013). Each spectrum was segmented into bins with a width of $0.005 \mathrm{ppm}$ between 0.2 and $10.0 \mathrm{ppm}$. The bins of residual $\mathrm{H}_{2} \mathrm{O}$ between 4.70 and $5.20 \mathrm{ppm}$ were excluded from all the NMR spectra. The total spectral area of the remaining bins was normalized to unity to facilitate the comparison between the spectra. All the NMR spectra were generalized $\log$ transformed $(\mathrm{glog})$ with a transformation parameter $\lambda=$ $2.0 \times 10^{-9}$ to stabilize the variance across the spectral bins and to increase the weightings of the less intense peaks (Ji et al. 2013). As described in details in our previous work, data were mean-centered before multivariate analysis ( $\mathrm{Ji}$ et al. 2013). Furthermore, the supervised multivariate data analysis methods, partial least squares discriminant analysis (PLS-DA) and orthogonal projection to latent structure with discriminant analysis (O-PLS-DA), were sequentially carried out to uncover and extract the statistically significant metabolite variations related to $\mathrm{Cd}$ exposures, as described previously (Feng et al. 2013). Metabolites were assigned following the tabulated chemical shifts and by using the software, Chenomx (Evaluation Version, Chenomx Inc., Edmonton, Alberta, Canada) (Ji et al. 2013).

\section{Determination of $\mathrm{Cd}$ in mussel samples}

The tissue samples of mussels for Cd determination were dried at $80^{\circ} \mathrm{C}$ to constant weights. The dried tissues were then digested in concentrated nitric acid $(70 \%$, Fisher Scientific) using a microwave digestion system (CEM, MAR5). The samples were heated in the microwave oven (heating to $200^{\circ} \mathrm{C}$ and holding at $200^{\circ} \mathrm{C}$ for $15 \mathrm{~min}$ ). All completely digested samples were diluted with ultrapure water for Cd determination using ICP-MS technique (Agilent 7500i, Agilent Technologies Co. Ltd, Santa Clara, CA, USA). GBW08571 Marine mussel tissue was used as a certified reference material for metal analysis to ensure internal quality assurance/quality control $(\mathrm{QA} / \mathrm{QC})$ practices (Li et al. 2012). The recovery of target elements, as tested by three individual spiking experiments, was restricted within $95.5-104.3 \%$ for $\mathrm{Cd}$. The Cd concentrations in Dshape larval, juvenile and adult mussel samples were expressed as means \pm standard deviation. For each treatment, there were five biological replicates used for $\mathrm{Cd}$ determination. One way analysis of variance (ANOVA) with Tukey's test was conducted on the Cd concentrations from control and Cd-exposed groups, respectively. A $p$ value less than 0.05 was considered statistically significant. The Minitab software (Version 15, Minitab Inc., USA) was used for the statistical analysis.

\section{Results and discussion}

Marine mussels have abundant metallothioneins and metallothionein-like proteins that can bind excessive heavy 
Table $1 \mathrm{Cd}$ concentrations in mussel samples at different life stages after $\mathrm{Cd}$ exposures for $48 \mathrm{~h}$

\begin{tabular}{lccl}
\hline $\begin{array}{l}\text { Cd accumulation } \\
\left(\mu \mathrm{g} \mathrm{g}^{1} \mathrm{dw}\right)\end{array}$ & \multicolumn{3}{l}{ Life stages of mussels } \\
\cline { 2 - 4 } & D-shape larvae & Juvenile & Adult \\
\hline Control & $1.92 \pm 0.85$ & $4.02 \pm 2.31$ & $2.89 \pm 0.78$ \\
Cd exposure & $40.26 \pm 5.79 * *$ & $46.33 \pm 6.16^{* *}$ & $9.30 \pm 4.74 *$ \\
\hline
\end{tabular}

Data were expressed as mean \pm standard deviation. Significant differences among groups were tested for by one-way analysis of variance with Tukey's test

$* p<0.05 ; * * p<0.01$

metal ions in their organs, such as digestive glands and gills (Bebianno and Serafim 1998). Therefore, marine mussels can accumulate high amounts of heavy metals and may be used as biomonitors of metal contaminants (Jernelov 1996). As shown in Table 1, the D-shape larval, juvenile and adult mussels exhibited significant $(p<0.05) \mathrm{Cd}$ accumulations in the whole tissues. In details, the average $\mathrm{Cd}$ concentrations in Cd-treated D-shape larval and juvenile mussels were extremely higher than that in corresponding control groups. However, the adult mussel samples showed a 3 times higher $\mathrm{Cd}$ concentration than that in the control samples (Table 1). Apparently, the D-shape larval and juvenile mussels had significantly higher $\mathrm{Cd}$ accumulations than the adult mussel. Previous studies have confirmed that the earlier life stages of mussels are more sensitive to heavy metals than the adults (Giacomin et al. 2013), which might be explained by the higher accumulation of heavy metals in the mussels at earlier life stages.

Figure 2 presents the typical ${ }^{1} \mathrm{H}$ NMR spectra from the D-shape larval, juvenile and adult mussel samples in control groups. A total of 31 metabolites, including amino acids (valine, leucine, isoleucine, alanine, arginine, glutamate, aspartate, etc.), intermediates in the Krebs cycle (succinate and fumarate), organic osmolytes (hypotaurine, dimethylglycine, betaine, taurine and homarine) and energy storage compounds ( $\alpha$-glucose, $\beta$-glucose, ATP and glycogen), were identified and labeled in Fig. 2. Visibly, the ${ }^{1} \mathrm{H}$ NMR spectrum from the D-shape larval mussel showed relatively high levels of alanine, succinate and fumarate, and low levels of glucose and glycogen compared with those in juvenile and adult mussels (Fig. 2). Alanine constitutes the major portion of end-product of glucose breakdown anaerobically, together with the intermediate in Krebs cycle, succinate, in invertebrates (Stokes and Awapara 1968). The high levels of alanine and succinate suggested the stronger anaerobiosis in the D-shape larval mussels (Stokes and Awapara 1968). As shown in Fig. 1c, the adult mussels had the highest level of the organic osmolyte, homarine, which implied that the adult mussel might mobilize homarine to regulate the osmotic balance. As a matter of fact, homarine

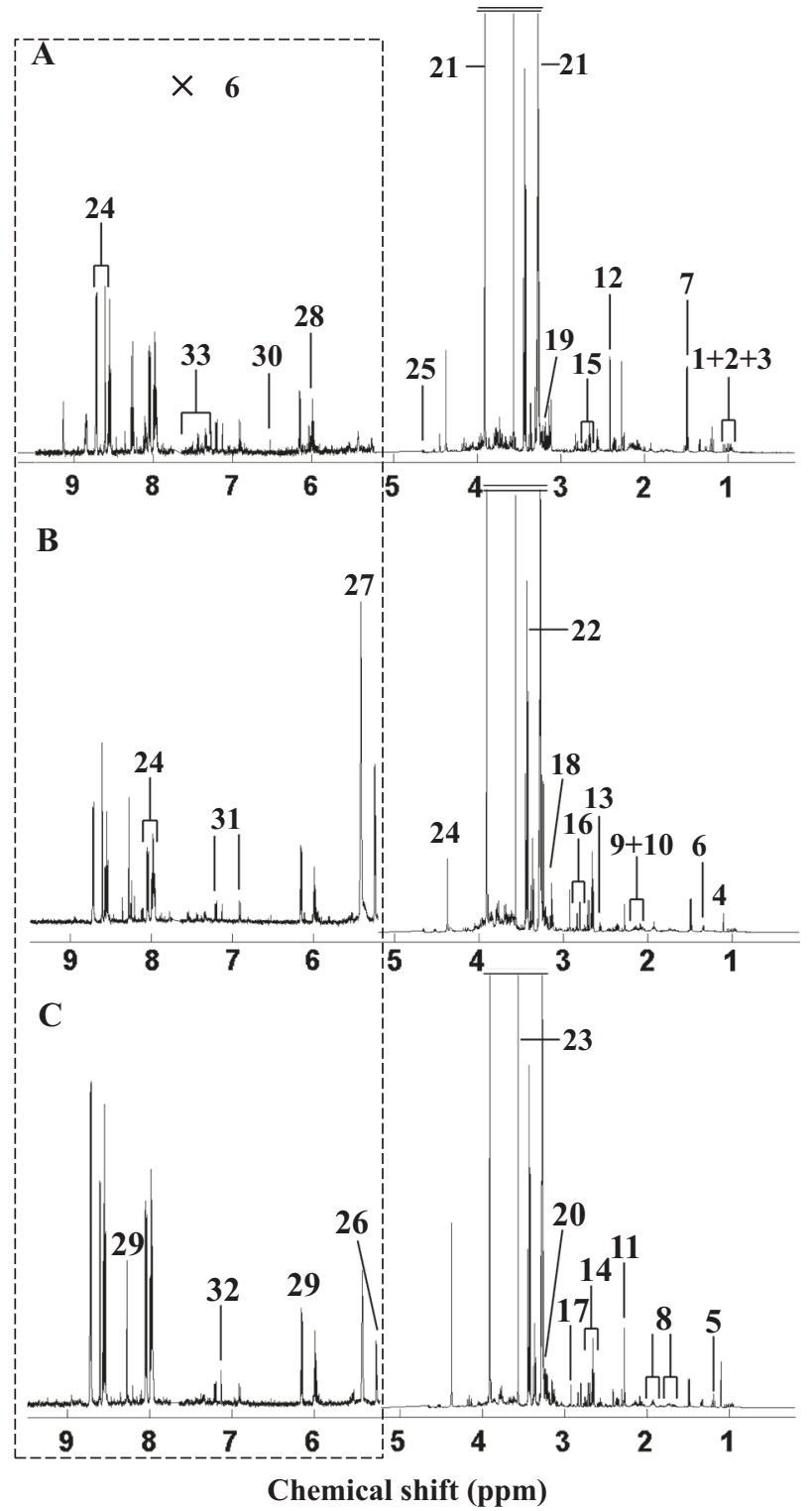

Fig. 2 Representative 1-dimensional $500 \mathrm{MHz}{ }^{1} \mathrm{H}$ NMR spectra of tissue extracts from control mussels $M$. galloprovincialis, a D-shape larvae, b juvenile and $\mathbf{c}$ adult groups. Keys: (1) isoleucine, (2) leucine, (3) valine, (4) unknown 1 (1.10 ppm), (5) ethanol, (6) threonine, (7) alanine, (8) arginine, (9) glutamate, (10) glutamine, (11) acetoacetate, (12) succinate, (13) $\beta$-alanine, (14) hypotaurine, (15) aspartate, (16) asparagine, (17) dimethylglycine, (18) malonate, (19) choline, (20) phosphocholine, (21) betaine, (22) taurine, (23) glycine, (24) homarine, (25) $\beta$-glucose, (26) $\alpha$-glucose, (27) glycogen, (28) unknown 2 (5.98 ppm), (29) ATP, (30) fumarate, (31) tyrosine, (32) histidine and (33) phenylalanine

is an important organic osmolyte in marine bivalves (Jones et al. 2008).

O-PLS-DA was performed on the NMR spectral data from control and Cd-treated mussel groups at three life stages, respectively (Fig. 3). All the O-PLS-DA models showed the robustness due to their reliable $\mathrm{Q}^{2}$ values 


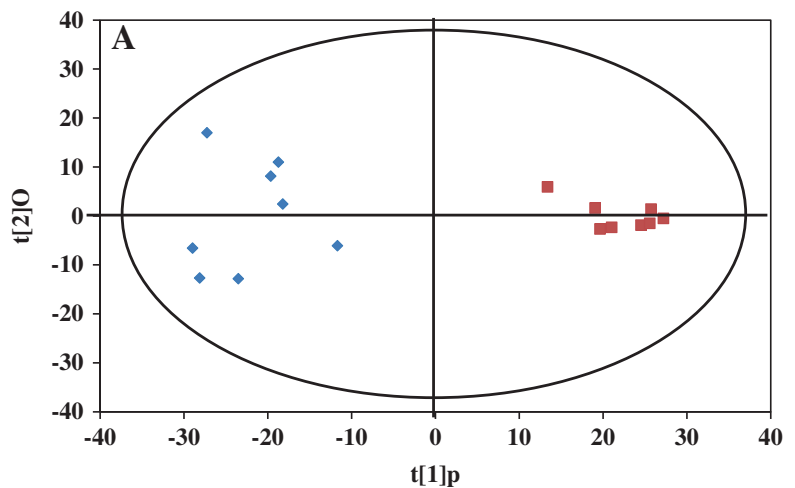

$R^{2} X=78.3 \%, Q^{2}=0.898$

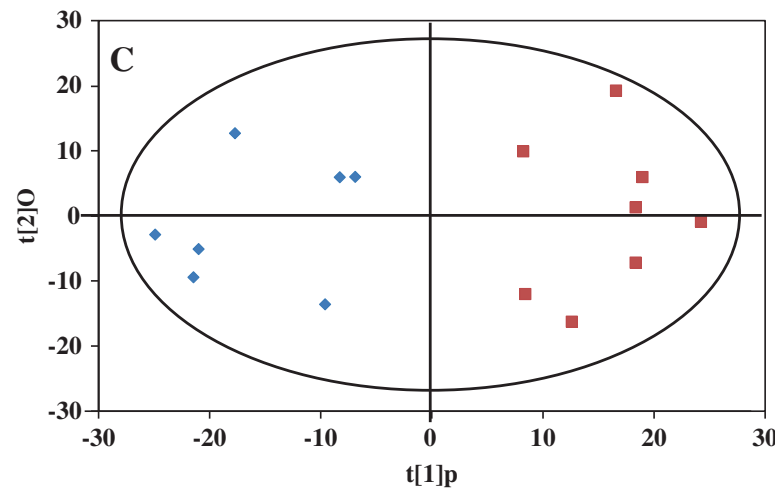

$R^{2} X=67.4 \%, Q^{2}=0.679$

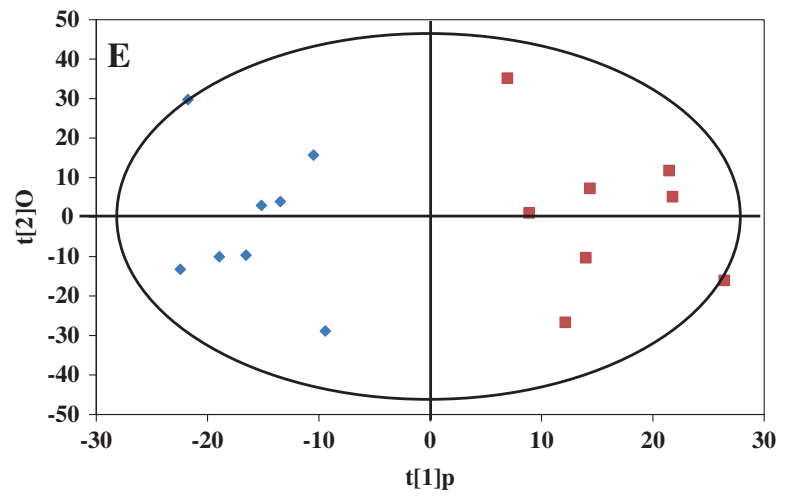

$R^{2} X=56.6 \%, Q^{2}=0.415$

Fig. 3 O-PLS-DA score plots derived from ${ }^{1} \mathrm{H}$ NMR spectra of tissue extracts from control (blue diamond) and Cd-exposed mussel groups (brown square), a D-shape larvae, $\mathbf{c}$ juvenile and e adult and corresponding coefficient plots $\mathbf{b}, \mathbf{d}$ and $\mathbf{f}$. The color map shows the significance of metabolite variations between the two classes (control and $\mathrm{Cd}$ treatment). Peaks in the positive direction indicate metabolites that are more abundant in the $\mathrm{Cd}$-exposed groups. Consequently, metabolites that

(Figs. 3a, c, e). From the loading plot (Fig. 3b), Cd exposure induced significant $(p<0.05)$ metabolic responses, including decreased branched chain amino acids (BCAAs), threonine, alanine, arginine, acetoacetate, succinate, $\beta$-alanine, hypotaurine, malonate, choline, glycine, glucose, glycogen and phenylalanine, and increased aspartate, phosphocholine and homarine, in D-shape larval mussels.
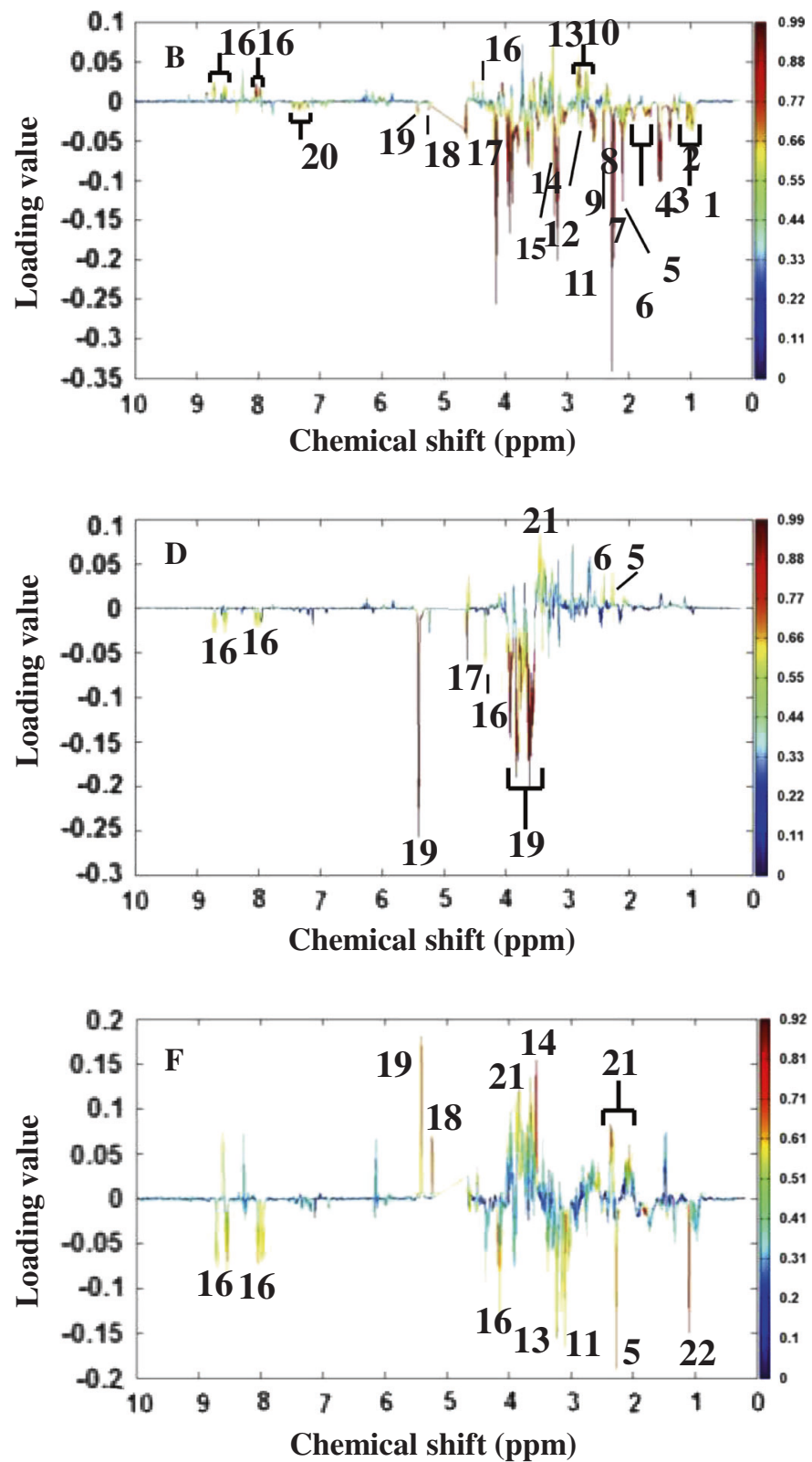

are more abundant in the control group are presented as peaks in the negative direction. Keys: (1) BCAAs, (2) threonine, (3) alanine, (4) arginine, (5) unknown 1 (2.08 ppm), (6) acetoacetate, (7) succinate, (8) $\beta$-alanine, (9) hypotaurine, (10) aspartate, (11) malonate, (12) choline, (13) phosphocholine, (14) glycine, (15) unknown 2 (3.95 ppm), (16) homarine, (17) $\beta$-glucose, (18) $\alpha$-glucose, (19) glycogen, (20) phenylalanine, (21) taurine and (22) unknown 3 (1.10 ppm) (color figure online)

In the juvenile mussels exposed to $\mathrm{Cd}$, acetoacetate and taurine were increased, and homarine, glucose and glycogen were decreased (Fig. 3d). As shown in Fig. 3f, malonate, phosphocholine and homarine were depleted, while glucose, glycogen and taurine were elevated in Cd-exposed adult mussels. Obviously, the D-shape larval mussel was 
the most sensitive life stage to $\mathrm{Cd}$ exposure due to the largest number of altered metabolites induced by $\mathrm{Cd}$.

As mentioned above, alanine and succinate are the main metabolites of anaerobiosis in invertebrate (Stokes and Awapara 1968). In addition, aspartate can be converted into succinate under anoxic conditions in mollusk (Graham and Ellington 1985). Interestingly, decreased succinate and alanine and increased aspartate were found in Cd-treated Dshape larval mussels, which suggested that $\mathrm{Cd}$ exposure reduced the anaerobiosis in D-shape larval mussels. In clam Ruditapes philippinarum, however, the anaerobiosis was enhanced by $\mathrm{Cd}$ exposure ( $\mathrm{Ji}$ et al. 2015). The contrary findings meant the species-specific effects in anaerobiosis induced by $\mathrm{Cd}$ in marine bivalves. Amino acids are involved in both osmotic regulation and energy metabolism (Viant et al. 2003). In Cd-treated D-shape larval mussels, amino acids including BCAAs, threonine, glycine, arginine and phenylalanine are decreased, together with glucose and glycogen. These metabolic responses probably implied that the D-shape larval mussels enhanced energy consumption to deal with the Cd stress. Choline and ATP can be catalyzed into phosphocholine and ADP by choline kinase (Pomfret et al. 1989). The depleted choline and elevated phosphocholine suggested that $\mathrm{Cd}$ enhanced the conversion of choline to phosphocholine in D-shape larval mussels. Malonate is a competitive inhibitor of the enzyme succinate dehydrogenase in animals (Dervartanian and Veeger 1964). Therefore, the decreased malonate might result in increased enzyme activity of succinate dehydrogenase and decreased succinate, which was observed in Cd-treated D-shape larval mussels as well. Both hypotaurine and homarine are known organic osmolytes playing vital roles in osmotic regulation in marine mussels (Jones et al. 2008). The altered osmolytes, including hypotaurine and homarine, demonstrated the osmotic stress induced by $\mathrm{Cd}$ in D-shape larval mussels.

In Cd-exposed juvenile mussels, the metabolic responses, including the increased acetoacetate and taurine and decreased homarine, were different compared with those from Cd-exposed D-shape larval mussels (Fig. 3d). However, glucose and glycogen were similarly decreased in $\mathrm{Cd}$ exposed juvenile mussels. Interestingly, these two energy storage compounds, glucose and glycogen, were significantly increased in Cd-treated adult mussels. It seemed that the adult mussels reduced energy consumption under $\mathrm{Cd}$ stress, which is a different strategy in energy metabolism to deal with $\mathrm{Cd}$ stress in adult mussels compared with the mussels at earlier life stages, D-shape larval and juvenile mussels. The altered osmolytes, increased taurine and decreased homarine, suggested the osmotic stress caused by $\mathrm{Cd}$ exposure in both juvenile and adult mussels via different metabolic pathways, compared with the metabolic responses, increased homarine and decreased hypotaurine in Cdexposed D-shape larval mussels. Acetoacetate is a ketone body synthesized from acetyl-coenzyme A (acetyl-CoA) as the end product of fatty acid metabolism. The depleted acetoacetate implied the reduced lipid metabolism in juvenile mussels. Malonate was depleted in Cd-treated adult mussels suggesting the reduced inhibition of enzyme succinate dehydrogenase in adult mussels caused by $\mathrm{Cd}$, which was consistent with the alteration of malonate in $\mathrm{Cd}$-treated D-shape larval mussels. The depleted phosphocholine implied the enhanced conversion of choline to phosphocholine, suggesting the disturbance in energy metabolism in adult mussels exposed to $\mathrm{Cd}$.

\section{Conclusions}

The toxicological effects of environmentally relevant concentration of $\mathrm{Cd}\left(50 \mu \mathrm{g} \mathrm{L} \mathrm{L}^{-1}\right)$ were characterized in three different life stages (D-shape larvae, juvenile and adult) of marine mussels $M$. galloprovincialis using NMR-based metabolomics. Basically, the metabolic responses indicated that the D-shape larval mussel was the most sensitive life stage to the $\mathrm{Cd}$ exposure. $\mathrm{Cd}$ induced osmotic stress in all the three life stages of mussels via different metabolic pathways. Cd reduced the anaerobiosis and enhanced the conversion of choline to phosphocholine in D-shape larval mussels. In juvenile mussels, the lipid metabolism was disturbed by the $\mathrm{Cd}$ exposure. Compared with the D-shape larval and juvenile mussels, the adult mussels reduced energy consumption to deal with $\mathrm{Cd}$ stress. This work demonstrated the differential toxicological effects of $\mathrm{Cd}$ in mussels M. galloprovincialis at different life stages.

Acknowledgments This work was supported by NSFC (41676114) and Natural Science Foundation of Shandong Province (No. JQ201310). The funders had no role in study design, data collection and analysis, decision to publish, or preparation of the manuscript. We thank Prof. Mark Viant (School of Bioscience, The University of Birmingham) for the use of ProMetab software.

\section{Compliance with ethical standards}

Conflict of interest The authors declare that they have no competing interests.

\section{References}

Bebianno MJ, Serafim MA (1998) Comparison of metallothionein induction in response to cadmium in the gills of the bivalve mollusks Mytilus galloprovincialis and Ruditapes decussates. Sci Total Environ 214:123-131

Bouilly K, Gagnaire B, Bonnard M, Thomas-Guyon H, Renault T, Miramand $\mathrm{P}$, Lapègue $\mathrm{S}$ (2006) Effects of cadmium on aneuploidy and hemocyte parameters in the Pacific oyster, Crassostrea gigas. Aquat Toxicol 7:149-156

Brindle JT, Antti H, Holmes E, Tranter G, Nicholson JK, Bethell HWL, Clarke S, Schofield PM, McKilligin E, Mosedale DE, 
Grainger DJ (2002) Rapid and noninvasive diagnosis of the presence and severity of coronary heart disease using ${ }^{1} \mathrm{H}-\mathrm{NMR}$ based metabonomics. Nat Med 8:1439-1445

Broeg K, Westernhagen HV, Zander S, Körting W, Koehler A (2005) The "bioeffect assessment index" (BAI): A concept for the quantification of effects of marine pollution by an integrated biomarker approach. Mar Pollut Bullet 50:495-503

Bundy JG, Spurgeon DJ, Svendsen C, Hankard PK, Weeks JM, Osborn D, Lindon JC, Nicholson JK (2004) Environmental metabonomics: Applying combination biomarker analysis in earthworms at a metal contaminated site. Ecotoxicology 13:797-806

Chang M, Wang W, Wang A, Tian TT, Wang P, Zheng Y, Liu Y (2009) Effects of cadmium on respiratory burst, intracellular $\mathrm{Ca}^{2+}$ and DNA damage in the white shrimp Litopenaeus vannamei. Comp Biochem Physiol Part C 149:581-586

Chester R (1990) Marine geochemistry. Allen \& Unwin, Australia, p 698

Company R, Serafim A, Bebianno MJ, Cosson R, Shillito B, FialaMédioni A (2004) Effect of cadmium, copper and mercury on antioxidant enzyme activities and lipid peroxidation on the gills of the hydrothermal vent mussel Bathymodiolus axoricus. Mar Environ Res 58:377-381

Dervartanian DV, Veeger C (1964) Studies on succinate dehydrogenase. I. Spectral properties of the purified enzyme and formation of enzyme-competitive inhibitor complexes. Biochim Biophys Acta 92:233-247

Feng J, Li J, Wu H, Chen Z (2013) Metabolic responses of HeLa cells to silica nanoparticles by NMR-based metabolomic analyses. Metabolomics 9:874-886

Giacomin M, Gillis PL, Bianchini A, Wood CM (2013) Interactive effects of copper and dissolved organic matter on sodium uptake, copper bioaccumulation, and oxidative stress in juvenile freshwater mussels (Lampsilis siliquoidea). Aquat Toxicol 144-145:105-115

Graham RA, Ellington WR (1985) Anaerobic aspartate metabolism and the formation of alanine in molluscan cardiac muscle: $\mathrm{A}^{13} \mathrm{C}$ NMR study. J Exp Zool 236:365-370
Jernelov A (1996) The international mussel watch: A global assessment of environmental levels of chemical contaminants. Sci Total Environ 188:S37-S44

Ji C, Zhou M, Zhao J, Wu H (2015) Multiple biomarkers of biological effects induced by cadmium in clam Ruditapes philippinarum. Fish Shellfish Immunol 44:430-435

Ji C, Wu H, Wei L, Zhao J, Yu J (2013) Proteomic and metabolomic analysis reveal gender-specific responses of mussel Mytilus galloprovincialis to 2,2',4,4'-tetrabromodiphenyl ether (BDE 47). Aquat Toxicol 140-141:449-457

Jones OAH, Dondero F, Viarengo A, Griffin JL (2008) Metabolic profiling of Mytilus galloprovincialis and its potential applications for pollution assessment. Mar Ecol Prog Ser 369:169-179

Li L, Liu X, You L, Zhang L, Zhao J, Wu H (2012) Uptake pathways and subcellular fractionation of $\mathrm{cd}$ in the polychaete Nereis diversicolor. Ecotoxicology 21:104-110

Lindon JC, Nicholson JK, Holmes E, Everett JR (2000) Metabonomics: metabolic processes studied by NMR spectroscopy of biofluids. Concepts Magn Reson 12:289-320

O'Connor TP (1998) Mussel watch results from 1986 to 1996. Mar Pollut Bullet 37:14-19

Pomfret EA, da Costa K-A, Schurman LL, Zeisel SH (1989) Measurement of choline and choline metabolite concentrations using high pressure liquid chromatography and gas chromatographymass spectrometry. Anal Biochem 180:85-90

Stokes TM, Awapara A (1968) Alanine and succinate as end-products of glucose degradation in the clam Rangia cuneata. Comp Biochem Physiol 25:883-892

Sun Q, Song J, Gao Y, Chen J, Sheng Y (2011) Distribution of heavy metals speciation and pollution in surface sediment from typical ecologically regions of Yantai coastal zone (In Chinese). Mar Sci 34:31-36

Viant MR, Rosenblum ES, Tjeerdema RS (2003) NMR-based metabolomics: a powerful approach for characterizing the effects of environmental stressors on organism health. Environ Sci Technol 37:4982-4989 